\title{
Precise comparisons of bottom-pressure and altimetric ocean tides
}

\author{
R. D. Ray ${ }^{1}$
}

Received 15 April 2013; revised 31 July 2013; accepted 3 August 2013; published 16 September 2013.

[1] A new set of pelagic tide determinations is constructed from seafloor pressure measurements obtained at 151 sites in the deep ocean. To maximize precision of estimated tides, only stations with long time series are used; median time series length is 567 days. Geographical coverage is considerably improved by use of the international tsunami network, but coverage in the Indian Ocean and South Pacific is still weak. As a tool for assessing global ocean tide models, the data set is considerably more reliable than older data sets: the root-mean-square difference with a recent altimetric tide model is approximately $5 \mathrm{~mm}$ for the $\mathrm{M}_{2}$ constituent. Precision is sufficiently high to allow secondary effects in altimetric and bottom-pressure tide differences to be studied. The atmospheric tide in bottom pressure is clearly detected at the $\mathrm{S}_{1}, \mathrm{~S}_{2}$, and $\mathrm{T}_{2}$ frequencies. The altimetric tide model is improved if satellite altimetry is corrected for crustal loading by the atmospheric tide. Models of the solid body tide can also be constrained. The free corenutation effect in the $\mathrm{K}_{1}$ Love number is easily detected, but the overall estimates are not as accurate as a recent determination with very long baseline interferometry.

Citation: Ray, R. D. (2013), Precise comparisons of bottom-pressure and altimetric ocean tides, J. Geophys. Res. Oceans, 118, 45704584, doi:10.1002/jgrc.20336.

\section{Introduction}

[2] Aiming for measurements of finer and finer precision is generally a prescription for progress in the natural sciences. For tidal phenomena, which result from forces across the entire Earth system, improved precision can reveal subtle, sometimes unexpected, effects. A now-classic example is precisely measuring tidally forced nutation and thereby discovering the excess flattening of the core-mantle boundary [Gwinn et al., 1986]. This paper attempts to obtain improved complementary measurements of deepocean tides with satellite altimetry and with bottompressure recorders (BPR). The result is concomitant insight into atmospheric and solid-earth tides.

[3] The original motivation for this work, it may be confessed, was to obtain better validation data for testing new global tide models, and thereby to update older work by Shum et al. [1997] and others. The data so obtained are indeed useful to that purpose; such model comparisons will be addressed elsewhere within the context of a much larger effort with a multitude of different tests (D. Stammer, personal communication, 2012). The present paper describes the construction and compilation of the improved pelagic

\footnotetext{
Additional supporting information may be found in the online version of this article.

${ }^{1}$ NASA Goddard Space Flight Center, Greenbelt, Maryland, USA.

Corresponding author: R. D. Ray, Code 698, NASA Goddard Space Flight Center, Greenbelt, MD 20771, USA. (richard.ray@nasa.gov)

C 2013. American Geophysical Union. All Rights Reserved. 2169-9275/13/10.1002/jgrc.20336
}

test data set and then explores what such improved precision might reveal.

[4] One of the standard and most widely used data sets for testing deep-ocean tide models was compiled in the early 1990 s by David Cartwright and Christian Le Provost and their colleagues. That data set comprised tidal harmonic constants from 102 stations, 50 from open-ocean island tide gauges, and 52 from seafloor pressure recorders. The data set was used by Shum et al. [1997, Table 3] and many others since. Section 2 describes construction of a new "ground truth" data set, based strictly on bottompressure data, which is found to be considerably more accurate than the old 102-station set. The remaining sections address effects that can be seen in the altimeter minus bottom-pressure differences, with section 4 devoted to atmospheric tides and section 5 to solid-earth tides.

[5] The paper addresses only tidal constituents of diurnal and higher frequency. No attempt is made to construct a reliable data set of long-period tides, even though there is a great need for one. In light of their longer periods and the higher background noise levels at those periods, a reliable compilation of station tide estimates would generally require considerably longer time series than those adopted here. Probably the most reliable test data set for longperiod tides is still that compiled by D. Luther and published as an appendix in Miller et al. [1993]; those were based on multidecade time series from small Pacific Ocean islands.

\section{New Deep-Ocean "Ground Truth" Data}

[6] The new test data set consists of tidal harmonic constants at 151 stations, distributed about the globe as shown 


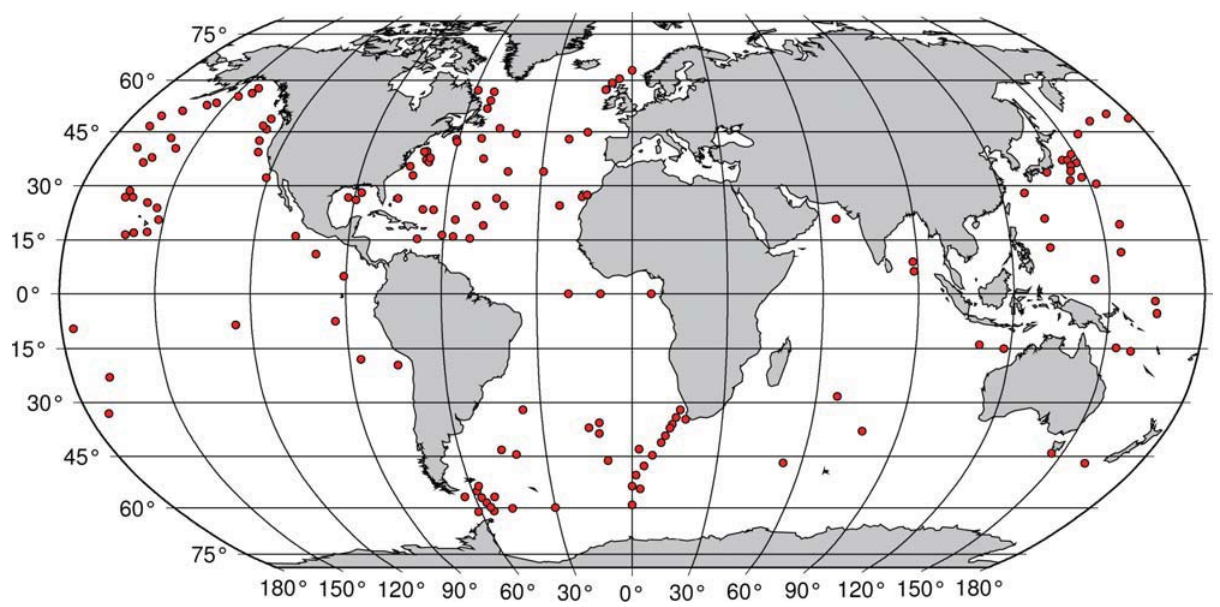

Figure 1. Locations of the 151 deep-ocean bottom-pressure stations.

in Figure 1. The stations are intentionally restricted to the deep open ocean, the traditional domain of satellite altimetry and where altimeter-based tide models are most accurate. Complementary test data sets restricted to shelf and near-coastal tides have also been developed [Lyard et al., 2006; Ray et al., 2011] and continue to be expanded and improved, but these will not be used in the present work.

[7] Tidal constants for a majority (86) of the 151 stations have been specially computed for this work from the measured bottom-pressure time series (sampled hourly or faster). In addition, new tidal analyses have been computed for 14 time series by Doug Luther and Martin Guiles and for six time series by Chris Hughes, and these are also reported here for the first time with their permissions.

\subsection{Station Selection Criteria}

[8] The 151 stations were selected based on several criteria. Foremost, only tidal constants derived from seafloor pressure records are used. Bottom-pressure data offer a number of advantages over island tide-gauge data: (1) Within the tidal frequency band and above, the background

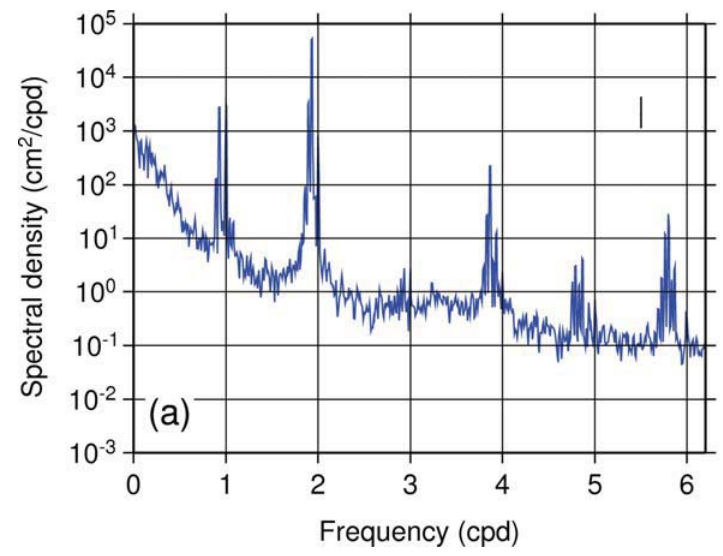

noise in bottom pressure is almost always markedly lower than surface height measurements; Figure 2, comparing the sea-level spectrum at the island of Nantucket with bottompressure spectrum from a site about $200 \mathrm{~km}$ distant, is a very typical example. (2) Bottom pressure is less sensitive to internal tides, which is desirable, assuming it is a barotropic model being tested and not a fully three-dimensional model. (3) Island gauges can be influenced by more localized effects, such as pronounced amplitude or phase distortions not representative of the deeper surrounding ocean [e.g., Farrow and Brander, 1971; Douillet, 1998].

[9] Second, station data were selected according to the length of pressure time series, with short time series rejected. Longer time series generally result, of course, in improved estimation of harmonic constants, and they also allow better separation of constituents with closely neighboring frequencies, such as the $\mathrm{P}_{1}-\mathrm{S}_{1}-\mathrm{K}_{1}$ triplet which are separated in frequency by only 1 cpy. Figure 3 summarizes in histogram form the time series lengths for all selected stations. No selected series is shorter than 90 days, $80 \%$ of the series are of at least 1 year duration and $35 \%$ are 2 years

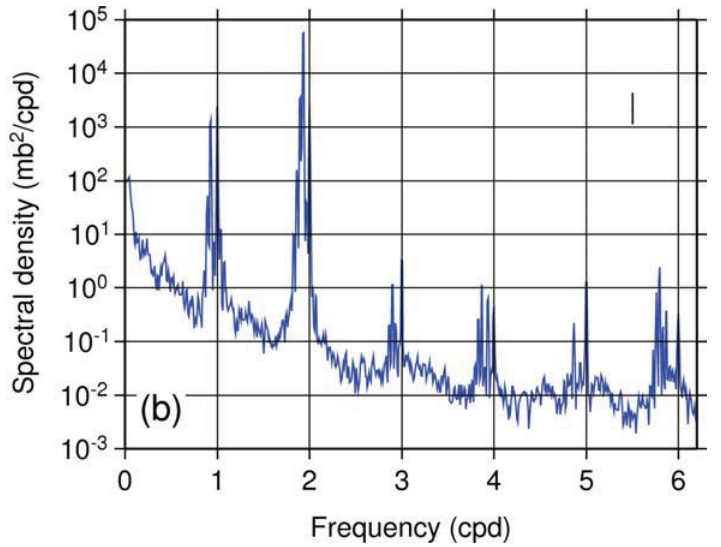

Figure 2. Spectrum of (a) sea level at Nantucket, USA, and (b) bottom pressure at DART station 44402 (near $39.5^{\circ} \mathrm{N}, 70.6^{\circ} \mathrm{W}$ ). The two stations are separated by roughly $200 \mathrm{~km}$. Both spectra are based on approximately 1.5 years of data. While diurnal and semidiurnal tidal peaks are comparable at both sites, the bottom-pressure background energy in Figure $2 \mathrm{~b}$ is much lower across the entire frequency range. 


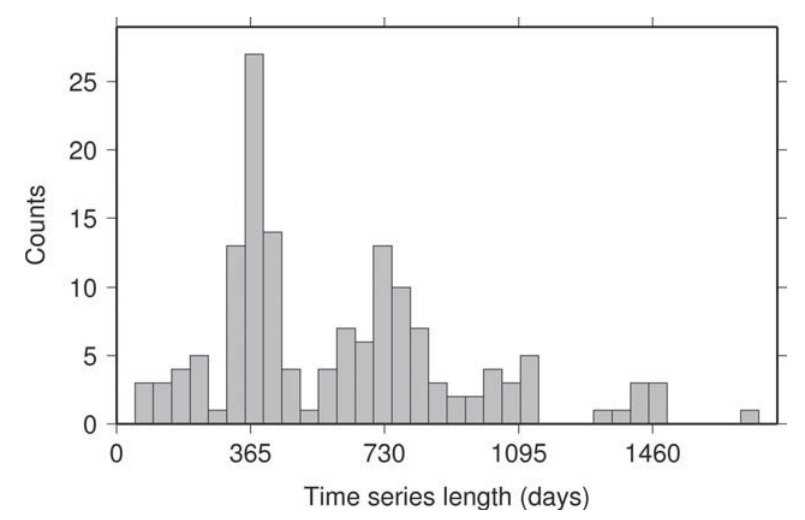

Figure 3. Histogram of lengths (in days) of all selected bottom-pressure time series. The shortest time series is 90 days. The median is 567 days.

or longer. It is only within the last few years that many of these very long time series have become available. Spencer and Vassie [1997] describe the first multiyear BPR time series (station MYRTLE) from the deep ocean that did not entail repeated redeployments.

[10] Third, stations located in close vicinity have been culled to avoid overweighting any small ocean area. This is only partially successful, and it is clear from Figure 1 that, for example, the South Atlantic is sampled far more heavily than the South Pacific. To some extent, the spacing of Topex/Poseidon altimeter tracks guided this culling of stations, since for some of the estimations in sections 4 and 5 the important criterion is that the sampling is independent. For example, Figure 4 shows the selected stations in the vicinity of the Drake Passage, and even though these stations are fairly close on a global or basin scale, the stations are still seen to sample the altimetry in a reasonably independent manner, based on which tracks are closest to which stations.

[11] This last criterion is the most subjective, but it is critical to avoid overweighting since some modern experiments deploy very tightly packed arrays. The KESS array [Donohue et al., 2010], for example, could alone provide 44 stations and would thereby overwhelm any global statistics. In cases like this, an attempt was made to maximize areal coverage by choosing a handful of the most widely separated stations. In many cases the choice of which nearby stations to select can be made based on time series length or some other judgment about data quality. A few examples will be noted below.

\subsection{Data Sources}

[12] Tidal harmonic constants derived from 414 bottompressure time series were previously collected in three publications sponsored by the International Association for the Physical Sciences of the Oceans (IAPSO): Cartwright et al. [1979]; Cartwright and Zetler [1985]; Smithson [1992]; along with additional data subsequently included in online archives at the U.K. National Oceanography Centre, Liverpool (formerly the Proudman Oceanography Laboratory (POL)). Many of these IAPSO time series, however, are either very short or represent redeployments at identical locations. For example, removing all series shorter than 200 days and all stations located within 100 $\mathrm{km}$ of another station, as well as all stations in water shallower than $250 \mathrm{~m}$, reduces the 414 time series to only 53, and many of these are near other, more modern stations. The IAPSO compilations are the source for 25 of our 151 stations. The shortest time series evident in Figure 3 were all IAPSO stations, but they were retained to help improve geographical coverage.

[13] An additional 15 stations, although part of the IAPSO compilation, have instead been extracted from the Global Undersea Pressure (GLOUP) archives, housed at POL. The GLOUP archive includes more extensive tidal analyses than those recorded in the older IAPSO booklets, which were generally restricted to eight major constituents, so the GLOUP data are therefore preferred for present purposes. Five GLOUP stations not included in the IAPSO compilations have also been added; they include two time series of length 730 days. GLOUP pressure data corresponding to IAPSO stations 1.1 .68 and 1.1 .69 , being two successive occupations on the Azores Rise but separated by only $10 \mathrm{mi}$, have here been combined to form a 11 month time series and tidally analyzed. The GLOUP data include stations from the well-known ACCLAIM program deployments in the South Atlantic and Southern Oceans [Spencer et al., 1993].

[14] Most of the IAPSO data, including many old analyses from the earliest days of seafloor records [e.g., Eyries et al., 1964; Snodgrass, 1968], are too short to meet our adopted criterion of 90 days duration. Fortunately, over the past two decades there have been a number of oceanographic campaigns collecting long series of pressure data, which can considerably augment the IAPSO compilations.

[15] Major recent BPR campaigns worth explicitly mentioning in this regard include:

[16] 1. MOVE: an array of three stations near $16^{\circ} \mathrm{N}$ between the Lesser Antilles Arc and the Mid-Atlantic

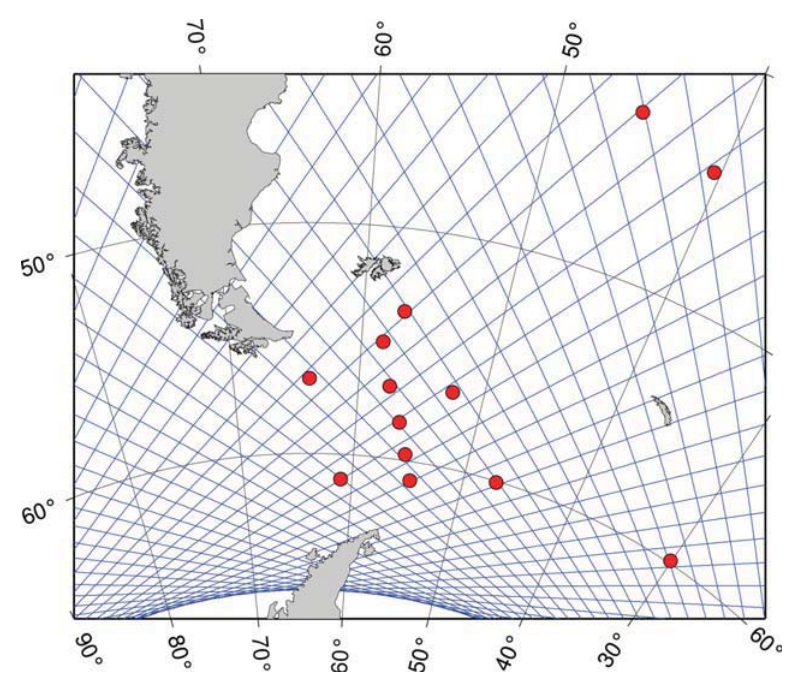

Figure 4. Locations of selected bottom-pressure stations near the Drake Passage, with ground tracks of the Topex/ Poseidon and Jason satellites. The two westernmost stations are from unpublished data obtained courtesy of R. Watts, T. Chereskin, and K. Donohue. 
Ridge [Kanzow et al., 2006] plus another station near $21^{\circ} \mathrm{N}$. The time series ranged from 591 to 809 days.

[17] 2. ASTTEX: five stations along a Topex/Poseidon (T/P) satellite groundtrack, southwest of Namibia in the South Atlantic [Ray and Byrne, 2010]. Data for 11 stations are available along this track; every other station was selected here, with an average separation of $255 \mathrm{~km}$. All series are of about 800 days duration.

[18] 3. AWI-ACC: seven selected stations in the South Atlantic, several of which extend the T/P line begun by ASTTEX, collected by the Alfred Wegener Institute (AWI). Six of these time series exceed 1000 days duration.

[19] 4. KESS: seven stations selected from a dense array of 44 stations sitting in or near the Kuroshio Extension [Donohue et al., 2010]. The seven were chosen to maximize areal coverage; the closest pair is separated by $168 \mathrm{~km}$.

[20] 5. HOME: nine stations surrounding the Hawaiian Ridge, collected by Alan Chave's group at Woods Hole Oceanographic Institution between April 2001 and May 2002 (about 380 days) and tidally analyzed by Doug Luther.

[21] 6. RAPID: a total of nine selected stations from a wide-ranging array of stations in the North Atlantic, including a mid-ocean line at $24.5^{\circ} \mathrm{N}$ and several arrays off the U.S. east coast, deployed to study rapid changes in the Atlantic overturning [Rayner et al., 2011; Elipot et al., 2013]. From six stations clustered very close to the African coast, just south of the Canary Islands, the two stations farthest from land (EB3 and EBH2) were selected, with separation distance $162 \mathrm{~km}$. Tidal constants for four of the selected RAPID stations were provided by Chris Hughes. $\mathrm{He}$ also provided constants for two stations in the Argentine Basin of the South Atlantic [Hughes et al., 2007].

[22] 7. URI-GOM: three stations from an array of stations in the central [Donohue et al., 2006] and western [Donohue et al., 2008] Gulf of Mexico. The three selected are the most widely separated of the time series that exceeded 1 year. Watts's group (University of Rhode Island) also provided data from several other campaigns back to 1996.

[23] 8. DART: a widely distributed set of 47 stations selected from the international (primarily American) tsunami early warning network, with 15 min data publicly available via the National Data Buoy Center. The DART data, originally recorded in units of pounds per square inch absolute (PSIA), are distributed in units of meters of equivalent water height after applying a uniform scaling of 670 $\mathrm{mm} /$ PSIA conversion; for the present work the units have been converted back to pressure in $\mathrm{Pa}$, taking 1 PSIA $=6894.757 \mathrm{~Pa}$.

[24] One station-Cobb Seamount, taken from Larsen and Irish [1975] - is worth mentioning, because it is the one site violating the deep water criterion, but only because the recorder sat at the peak of a barely submerged seamount (depth $35 \mathrm{~m}$ ) in an otherwise open expanse of the deep ocean.

[25] Particularly important for the present work is the DART array, comprising nearly one third of the whole BPR data set. Its wide distribution of stations considerably strengthens coverage of the global ocean, especially following the DART program's extensive augmentation after the great 2004 Sumatra earthquake and tsunami. The new

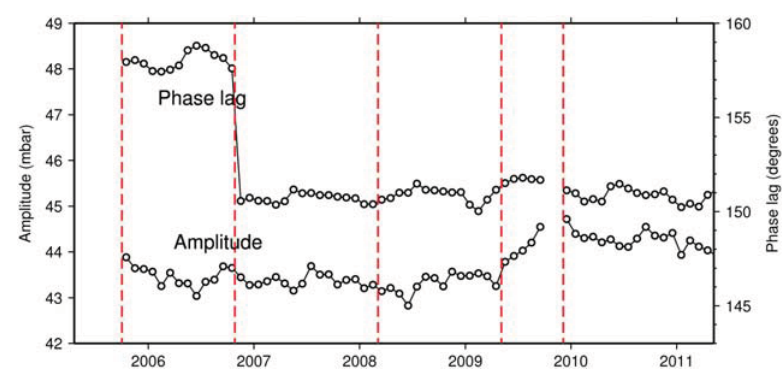

Figure 5. Monthly estimates of the amplitude and phase lag of the $\mathrm{M}_{2}$ tide for DART station 46412, located west of San Diego, California. Vertical dashed lines mark times of redeployment of the bottom-pressure recorder. Data obtained in 2010 and afterwards were about $27 \mathrm{~km}$ distant from earlier data. The phase jump in late 2006 probably results from a time-tag error since a similar offset, but half as large, occurs for the $\mathrm{O}_{1}$ constituent.

stations add valuable data in some previously unsampled regions. Use of the DART data, however, does require some care for at least two reasons: (1) There are a fair number of outliers, or generally suspect data, which require special handling. (These likely stem from inevitable problems associated with real-time operations from the seafloor.) Andreas Macrander (AWI), who has processed DART and other BPR data as part of validation exercises for satellite gravity missions [Macrander et al., 2010], has very kindly made available his corrected time series. Of the 47 DART tidal analyses reported here, 36 are based on Macrander's time-series data. (2) Like any in situ instrumentation in harsh environments, DART pressure recorders are periodically serviced and redeployed. The redeployments are generally close to previous deployments for a given station, but sometimes insufficiently close to sample precisely the same tide. Figure 5 displays a possible example of this problem for DART station 46412, located off the coast of California. Shown is a series of monthly estimates of the $\mathrm{M}_{2}$ tide for this station, derived by a response analysis, with vertical lines marking times of redeployments. According to available documentation, the May 2009 move entailed the largest change in position, about $27 \mathrm{~km}$ northeast toward the California coast, and the estimated amplitudes do seem to reflect this, although the slow rise in mid2009 is curious and unexpected (it is unlikely to be from initial deployment stresses, since the instrument had actually been deployed in July 2008, overlapping the earlier deployment). The large phase jump in October 2006 corresponds to an insignificant change in horizontal position, only about $4 \mathrm{~km}$. In fact, the 2006 phase jump of approximately $7^{\circ}$ is almost surely the result of a time-tag error of approximately $15 \mathrm{~min}$; the phase of $\mathrm{O}_{1}$ jumped by a corresponding amount of $3-4^{\circ}$. For this DART station the adopted tidal constants are those computed for the period November 2006 through May 2009 (and obviously assigned to the old location). Station 46412 is not the only DART station with such problems.

[26] A few DART stations were unused if they fell too near other stations. For example, DART station 51407 is close to Hawaii and unneeded in light of the HOME array. Station 55013, only $44 \mathrm{~km}$ from 55015 but with a shorter 
time series, is similarly unneeded. On the other hand, 44402 is preferred over RAPID station RS3 (separated by $75 \mathrm{~km}$ ) because it has a longer time series.

[27] A small number of stations that passed initial acceptance criteria were still rejected because the data were subsequently deemed suspect. For example, station M2.5 of the MOVE array appears to have a timing error of roughly $20 \mathrm{~min}$, detected in part by comparison to nearby stations M2 and M3. But the station is unneeded in any event because of these nearby stations, so no loss of coverage arises by rejecting M2.5. The most conspicuous outliers were the five stations in the 1986-1987 BEMPEX array of the North Pacific, which were based on constants reported by Filloux et al. [1991] and subsequently included in the IAPSO catalog [Smithson, 1992]. The suspicious data have recently been traced to a flawed tidal analysis, and Doug Luther, who has the original time series, has kindly provided constants from a new tidal analysis that corrects the earlier errors.

\subsection{Tidal Analysis of BPR Data}

[28] A total of 86 BPR time series were tidally analyzed as part of the present study. Harmonic constants for 25 stations, either GLOUP stations or some RAPID stations, were computed by C. Hughes and others at the Proudman Laboratory. Constants for an additional 14 stations were obtained from Luther. The remaining 26 stations were from the IAPSO compilations or other published sources [e.g., Larsen and Irish, 1975].

[29] All stations that entail time series shorter than 160 days were extracted from the IAPSO compilations. The tidal analyses of those time series were obviously performed by a variety of different investigators using a variety of methods. The shortest time series were, very justifiably, analyzed by a response analysis, using either a reference tidal prediction, if available and appropriate, or the equilibrium tide [Cartwright et al., 1969].

[30] All other time series were analyzed by least-squares harmonic methods, with standard adjustments for nodal and perigee variations within constituents. None of the time series was long enough, however, to support separating third-degree from second-degree tides. Third-degree tides are generally reduced in amplitude relative to seconddegree tides by a factor $1 / 60$ - the lunar parallax - and rarely exceed $1 \mathrm{~cm}$ even in resonance [Cartwright, 1975], except in isolated gulfs that do not apply here (e.g., the third-degree $\mathrm{N}_{2}$ constituent reaches $2.5 \mathrm{~cm}$ on the coast of Maine). Thus, the effects of inseparation should be minor and were deemed an acceptable tradeoff of using BPR data.

[31] The number of constituents included in any station analysis varied according to both the length of time series and the estimation noise levels. In the distributed data accompanying this paper, a reduced set of common constituents is used for all tides, although not all are available for all stations. For example, of the 151 stations, only 121 include constituent $2 \mathrm{Q}_{1}$. Selected compound tides have been included up to species 4 .

[32] Following each tidal analysis the estimated amplitudes were adjusted to account for any temporal averaging of the raw pressure measurements. This adjustment, often overlooked but necessary for high-precision work, arises because many of the BPR time series consist not of spot values of the pressure at discrete times but rather averages over some interval, often $1 \mathrm{~h}$. Such averaging will slightly reduce the tidal amplitude of a constituent with period $T$ by the amount (e.g., Malin and Chapman [1970], Appendix A)

$$
\frac{1}{P} \int_{-P / 2}^{P / 2} \cos (2 \pi t / T) \mathrm{d} t=(T / \pi P) \sin (\pi P / T)
$$

where $P$ is the averaging interval. Thus, when using hourly averages, semidiurnal amplitudes should be increased by a factor 1.0115, quarter-diurnal amplitudes by 1.0472. Tidal constants for the ASTTEX, KESS, the Gulf of Mexico, and older arrays from Watts's group (e.g., from the Labrador Sea) have been so adjusted. Recent data from POL are generally $15 \mathrm{~min}$ averages, which results in very little averaging error, so no adjustments have been done to these data. The DART data generally consist of 15 min spot readings, so no adjustment is warranted. The BEMPEX and HOME data were also analyzed (by Luther and Guiles) at $15 \mathrm{~min}$ sampling. Owing to lack of documentation, no corrections can be made to the old IAPSO data.

[33] A second adjustment was done to attempt to remove from the bottom pressures the effects of atmospheric tides. This is discussed in more detail in section 4 below. To the extent that this removal is successful, the final bottompressure tidal constants then represent purely the ocean tide.

\subsection{Conversion of Bottom Pressure to Equivalent Surface Elevation}

[34] How tidal bottom-pressure fluctuations are to be converted to equivalent sea-surface heights for comparison with altimetry is a subject of some importance to the remainder of this paper. To the extent the subject is mentioned in the tidal literature, the conversion is generally performed by dividing the pressure by $g \rho_{\text {mean }}$, where $\rho_{\text {mean }}$ is the mean density of the water column and $g$ is the local acceleration of gravity, and more often by simply employing the conversion factor $1.01 \mathrm{mbar}^{-1}$ [e.g., Smithson, 1992].

[35] A simple thought experiment reveals the inadequacy of this conversion. Consider a homogeneous ocean where density is solely a function of compression from the weight of the overlying water column. Then a tidal fluctuation at the surface of height $\eta$ results in a water column identically compressed as before, save for a slab of water at the seafloor of thickness $\eta$. The pressure fluctuation at the bottom thus corresponds to $\eta g \rho_{\text {bottom }}$.

[36] The subject becomes more complex for an inhomogeneous ocean in which internal tides occur. Since all tidal analyses here arise from long time series representing in essence temporal means of harmonic constants, only temporally coherent internal tides are potentially of importance. At this stage, however, global maps of coherent internal tides - even for mode- $1 \mathrm{M}_{2}$ - are too unreliable to allow us to account for the effects in any systematic way; the topic is an ongoing research concern [e.g., Dushaw et al., 2011] and, in fact, will probably require additional new data from future satellite missions [e.g., Fu et al., 2012]. Thus, internal tides are ignored in what follows. At some 

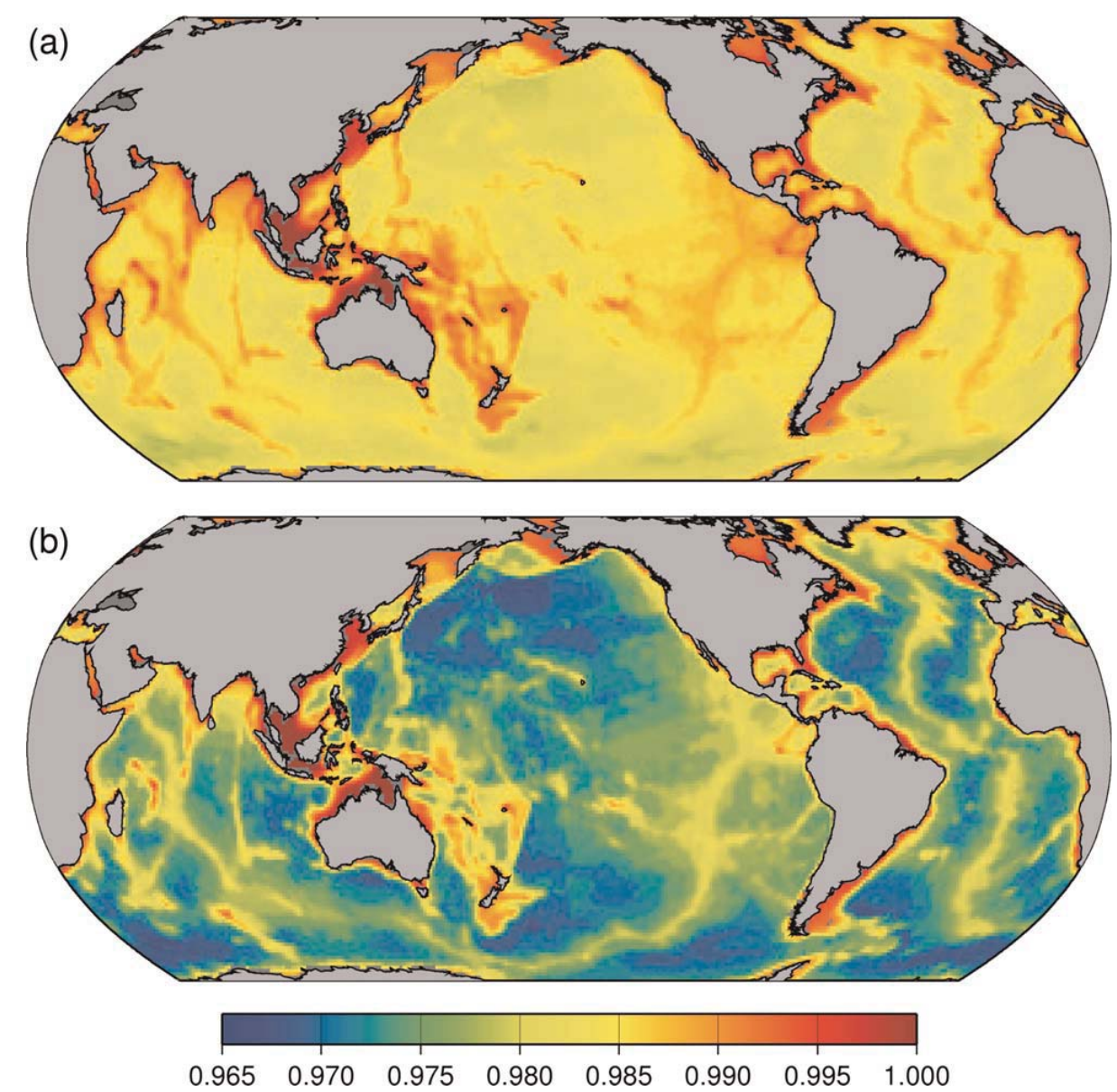

Figure 6. Scale factor for converting bottom pressure to equivalent sea-surface height, in units of $\mathrm{cm}$ $\mathrm{hPa}^{-1}$. (a) The standard conversion factor $1 / g \rho_{\text {mean }}$ where $\rho_{\text {mean }}$ is the column-mean seawater density. (b) The conversion factor from equation (1). Note that in shallow seas the conversion factor approaches unity.

future time, the influence from internal tides should be reconsidered, because it could well result in further improved precisions between BP and altimetric tides.

[37] The following two paragraphs follow a line of thought suggested by C. Garrett (personal communication, 2009). Consider a point in the ocean of depth $H$. The bottom pressure is $g H \rho_{\text {mean }}$. Now consider a tidal convergence at this location, which acts to increase mass at every level of the water column by a small fraction $\varepsilon$. The sea-surface height fluctuation $\eta$ would be $\varepsilon H$ if additional compression of the water column is ignored, but with compression it must be slightly less than this. The pressure $p$ at every level, including the bottom, does increase by the same fraction $\varepsilon$; the local density thus increases proportionally by the fraction $\varepsilon p \partial \rho / \partial p=\varepsilon p / c^{2}$, where $c$ is the speed of sound.

[38] The thickness of each level (i.e., distance between isopycnals) changes in two ways - increasing by $\varepsilon$ from the additive mass and decreasing by compression from the extra overlying mass; that is, the thickness changes by $\varepsilon\left(1-p / \rho c^{2}\right)$. The second correction term is roughly $g z / c^{2}$ at depth $z$ and its average over the water column is $g H / 2 c^{2}$, which provides a compression correction to the standard pressure-to-elevation conversion. Thus, for a bottom- pressure tidal fluctuation $\delta p_{b}$ the corresponding surface elevation is

$$
\eta=\delta p_{b}\left(1-g H / 2 c^{2}\right) /\left(g \rho_{\text {mean }}\right)
$$

[39] The factor $\left(1-g H / 2 c^{2}\right)$ in deep water amounts to about a $1 \%$ adjustment, and less in shallower water, so it is small but still possibly important. The overall conversion factor $\eta / \delta p_{b}$ that converts bottom pressure to equivalent sea-surface height is shown in Figure 6, where the relevant seawater densities (and the implied speed of sound) are extracted from the World Ocean Atlas and $g$ is taken as normal gravity, dependent on latitude. The upper panel displays the traditional factor $1 / g \rho_{\text {mean }}$ and the lower panel displays the right-hand factor from equation (1). The largest differences arise in the deepest parts of the ocean where compressibility comes more into play. Note that in shallow seas the conversion factor approaches unity, $1 \mathrm{~cm} / \mathrm{mbar}$.

[40] In fact, the altimeter-minus-BP tide differences are sufficiently precise to be sensitive to this method of converting between bottom pressure and equivalent seasurface height. Root-mean-square (rms) differences between BPR tides and the GOT4.8 model, discussed in much more detail in the next section, are shown in Table 1 
Table 1. RMS Differences $(\mathrm{cm})$ Between BP Stations and Model GOT4.8 According to How Bottom Pressure Is Converted to Equivalent Elevation ${ }^{\mathrm{a}}$

\begin{tabular}{lcc}
\hline Conversion Method & $\mathrm{M}_{2} \mathrm{RMS}$ & $\mathrm{O}_{1} \mathrm{RMS}$ \\
\hline $1.00 \mathrm{mb} / \mathrm{cm}$ & $0.777 \pm 0.039$ & $0.411 \pm 0.020$ \\
$1.01 \mathrm{mb} / \mathrm{cm}$ & $0.586 \pm 0.034$ & $0.357 \pm 0.018$ \\
$g \rho_{\text {mean }}$ & $0.517 \pm 0.034$ & $0.323 \pm 0.019$ \\
Equation (1) & $0.510 \pm 0.033$ & $0.296 \pm 0.020$ \\
\hline${ }^{\text {a Uncertainties }}$ are standard deviations computed & via bootstrap \\
resampling. & &
\end{tabular}

as a function of the method used to effect the pressure conversion. For both $\mathrm{M}_{2}$ and $\mathrm{O}_{1}$ constituents the smallest rms values are obtained when using equation (1), with $\mathrm{O}_{1}$ showing clearest improvement over the more standard factor $1 / g \rho_{\text {mean }}$. The simpler conversions, such as a constant 0.99 $\mathrm{cm} / \mathrm{mbar}$ factor, result in considerably higher rms differences, and they should probably be avoided except for use as a quick rule of thumb.

[41] Finally for the special case of a homogeneous, but compressible, fluid that is neutrally stable, the potential density is constant so the density lapse rate is strictly the adiabatic lapse rate, $\partial \rho / \partial z=-\rho g / c^{2}$. Thus, $\rho(z)=\rho_{s} \exp$ $\left(-g z / c^{2}\right) \approx \rho_{s}\left(1-g z / c^{2}\right)$, where $\rho_{s}$ is the surface density and the approximation is valid because $\left(g z / c^{2}\right)$ is generally of order $O\left(10^{-2}\right)$ or smaller. Then

$$
\frac{\rho_{\text {mean }}}{\rho_{\text {bottom }}}=\frac{1+g H / 2 c^{2}}{1+g H / c^{2}}=1-g H / 2 c^{2}
$$

so that (1) yields $\delta p_{b}=\eta g \rho_{\text {bottom }}$, as noted above.

\section{Comparisons of BPR and Altimetric Tides}

[42] Table 2 is the main result of comparing the new BPR tide data set with the global altimetric tide solution GOT4.8. (Solution GOT4.8 and some variants of it are
Table 3. RMS Differences (cm) With GOT4.8

\begin{tabular}{lccccc}
\hline & $\mathrm{O}_{1}$ & $\mathrm{~K}_{1}$ & $\mathrm{~N}_{2}$ & $\mathrm{M}_{2}$ & $\mathrm{~S}_{2}$ \\
\hline Old 102-station data set & 0.77 & 1.02 & 0.64 & 1.45 & 0.83 \\
New 151-station data set & 0.30 & 0.42 & 0.25 & 0.51 & 0.37 \\
\hline
\end{tabular}

described in Appendix A. Since the altimetry is sensitive to the geocentric tide, the solid-earth contribution must be removed to yield a true ocean tide; details for this are discussed in Appendix B.)

[43] The root-mean-square (rms) differences of Table 2 were computed from all in-phase and quadrature component station-model differences, where model values were evaluated by bilinear interpolation at the locations of the 151 BPR stations. These differences are tabulated for 18 constituents. The table also includes a second statistic, the median of absolute differences, which is less sensitive to outliers (although such sensitivity can be useful for testing models or in other applications).

[44] The quoted uncertainties in Table 2 represent an attempt to gauge statistical variability of the tabulated values. Such assessment is necessary when, for example, comparing different rms values from different models or different corrections. The uncertainties here are based on a bootstrap resampling of the station data (with replacement), which seems preferable to relying on dubious distributional assumptions. The tabulated quantities represent 1 standard deviation from these bootstrap resamplings.

[45] The agreement between the BPR and altimetric tides must be considered quite good, well below $1 \mathrm{~cm}$ for all constituents. The largest rms of $5.1 \mathrm{~mm}$ coincides with the largest constituent, $\mathrm{M}_{2}$, while smaller constituents (identified by the rms "signal" column in the table) show better agreements.

[46] The quality of the new BPR data set is brought out clearly in Table 3, which compares rms differences (again with GOT4.8) for the five largest tides against similar calculations made with the old standard 102-station data set,

Table 2. Comparisons Between Model GOT4.8 and Bottom-Pressure Tides ${ }^{\mathrm{a}}$

\begin{tabular}{lcccc}
\hline Tide & Number Stations & BPR Signal RMS $(\mathrm{cm})$ & RMS Diff. $(\mathrm{cm})$ & Median Abs.Diff. (cm) \\
\hline $2 \mathrm{Q}_{1}$ & 121 & 0.2 & $0.085 \pm 0.007$ & $0.040 \pm 0.004$ \\
$\mathrm{Q}_{1}$ & 148 & 1.8 & $0.164 \pm 0.007$ & $0.107 \pm 0.008$ \\
$\mathrm{O}_{1}$ & 151 & 8.8 & $0.296 \pm 0.020$ & $0.181 \pm 0.012$ \\
$\mathrm{P}_{1}$ & 146 & 0.0 & $0.234 \pm 0.011$ & $0.146 \pm 0.008$ \\
$\mathrm{~S}_{1}$ & 117 & 12.5 & $0.331 \pm 0.029$ & $0.187 \pm 0.014$ \\
$\mathrm{~K}_{1}$ & 151 & 0.7 & $0.423 \pm 0.016$ & $0.303 \pm 0.015$ \\
$\mathrm{~J}_{1}$ & 125 & 0.4 & $0.178 \pm 0.009$ & $0.110 \pm 0.008$ \\
$\mathrm{OO}_{1}$ & 124 & 0.8 & $0.265 \pm 0.013$ & $0.151 \pm 0.013$ \\
$2 \mathrm{~N}_{2}$ & 123 & 1.0 & $0.271 \pm 0.014$ & $0.146 \pm 0.014$ \\
$\mu_{2}$ & 123 & 1.1 & $0.409 \pm 0.028$ & $0.226 \pm 0.021$ \\
$\mathrm{~N}_{2}$ & 151 & 30.2 & $0.252 \pm 0.013$ & $0.156 \pm 0.007$ \\
$\nu_{2}$ & 121 & 0.8 & $0.075 \pm 0.003$ & $0.048 \pm 0.003$ \\
$\mathrm{M}_{2}$ & 151 & 0.6 & $0.510 \pm 0.033$ & $0.251 \pm 0.022$ \\
$\mathrm{~L}_{2}$ & 124 & 11.2 & $0.250 \pm 0.020$ & $0.124 \pm 0.010$ \\
$\mathrm{~T}_{2}$ & 118 & 3.1 & $0.130 \pm 0.007$ & $0.075 \pm 0.008$ \\
$\mathrm{~S}_{2}$ & 151 & 0.2 & $0.369 \pm 0.022$ & $0.235 \pm 0.012$ \\
$\mathrm{~K}_{2}$ & 146 & $0.209 \pm 0.011$ & $0.129 \pm 0.011$ \\
$\mathrm{M}_{4}$ & 130 & $0.089 \pm 0.004$ & $0.062 \pm 0.004$ \\
\hline
\end{tabular}

${ }^{\mathrm{a}}$ Uncertainties are standard deviations computed via bootstrap resampling. 


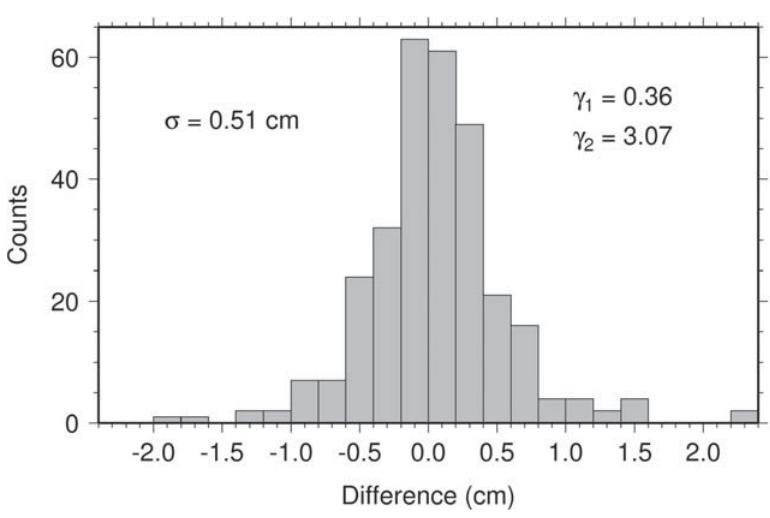

Figure 7. Histogram of in-phase and quadrature component differences between bottom-pressure stations and the GOT4. 8 model, for the $\mathrm{M}_{2}$ constituent. The standard deviation $\sigma$ corresponds closely to the rms value quoted in Table 2. Parameters $\gamma_{1}$ and $\gamma_{2}$ are skewness and excess kurtosis, respectively; the latter suggests the distribution is "longtailed" with possible outliers. In fact, this is clear from the presence of several differences exceeding $3 \sigma$.

mentioned in section 1. The older data set has been used widely over the past two decades, especially for testing new tidal models, but Table 3 suggests it can now be considered obsolete. Note in particular that the rms for $\mathrm{M}_{2}$ drops by a factor of 3 for the new test data set. As mentioned above, about half of the old data set is based on island tide-gauge stations that may not properly reflect the open-ocean tide seen by altimetry. Island data may also be perturbed by internal tides, which are for the most part filtered out of altimetric tide solutions like GOT. Furthermore, about one fifth of the old data set is based on time series of duration 1 month or less, and thus inherently much less precise than the tidal estimates compiled here. In light of all these reasons, it is perhaps not surprising, but nonetheless still satisfying, to see the rms for $\mathrm{M}_{2}$ drop from $1.5 \mathrm{~cm}$ to $0.5 \mathrm{~cm}$.

[47] A more detailed view of the station-model tide differences for $\mathrm{M}_{2}$ can be seen in Figures 7 and 8. A histogram of the in-phase and quadrature component differences is shown in Figure 7. Relative to a normal distribution, the residuals are somewhat leptokurtic, suggestive of the presence of outliers, which could be in either the station data or the altimeter estimates or both. It is relevant to note, however, that the four stations with largest residuals are all from the old IAPSO compilation (specifically stations 1.1.71, 1.2.107, 2.1.17, and 4.1.4). In fact, if the BPR stations are partitioned into subsets, the $\mathrm{M}_{2} \mathrm{rms}$ difference for the 26 IAPSO stations is $0.79 \pm 0.11 \mathrm{~cm}$, but only $0.34 \pm 0.04 \mathrm{~cm}$ for the 47 DART stations.

[48] A standard scatterplot diagram displaying station versus model amplitudes or phases is not especially informative because at full scale nearly all points appear to fall on a straight line of unit slope. It is more revealing instead to plot amplitude or phase differences as a function of amplitude, which is shown in Figure 8 for $M_{2}$ and Figure 9 for $\mathrm{O}_{1}$. While all differences are small, in keeping with the above statistics, Figure 8 reveals a slight tendency for GOT4.8 amplitudes to exceed BPR amplitudes above about
$45 \mathrm{~cm}$. This discrepancy does not appear to be a simple scale error-for which many possible explanations might be offered-but more like a simple offset, which is harder to explain. The mean amplitude difference for all stations is $0.77 \pm 0.41 \mathrm{~mm}$, but for amplitudes greater than $45 \mathrm{~cm}$ the mean difference is $2.8 \pm 0.8 \mathrm{~mm}$. A similar discrepancy in large amplitudes is seen in $\mathrm{N}_{2}$ (not shown). However, the tendency in $\mathrm{O}_{1}$ appears opposite (Figure 9), so perhaps both are statistical flukes. The positive offset near very small $(1 \mathrm{~cm})$ amplitudes probably owes to additive noise in the GOT4.8 solution. There are no statistically significant mean differences in phase in either diagram; larger phase scatter for small amplitudes is, of course, expected and of no great concern.

[49] Another curiosity can be noticed in Table 2: the model-station differences for $\mu_{2}$ are anomalously large. Now the GOT solutions for $\mu_{2}$, as well as the neighboring $2 \mathrm{~N}_{2}$, are not direct estimates but rather are extrapolated from the tidal admittances at $\mathrm{N}_{2}$ and $\mathrm{M}_{2}$. Yet $\mu_{2}$ seems relatively more error prone than $2 \mathrm{~N}_{2}$ even though the extrapolation is over a comparable frequency range (about 1 cycle/ month below $\mathrm{N}_{2}$ ). In shallow water $\mu_{2}$ is often significantly perturbed by $\mathrm{M}_{2}-\mathrm{S}_{2}$ nonlinear interactions, which inhibits inference calculations, but the effect is expected to be slight in deep water. At Honolulu, however, Munk and Cartwright [1966] noticed a substantial offset of the semidiurnal admittance at $\mu_{2}$. Perhaps like $\mathrm{M}_{4}$ in the deep Atlantic [Lyard et al., 2006; Ray, 2007], a significant part of $\mu_{2}$ is nonlinearly generated in shallow waters and freely propagates into the deep ocean. If true, this suggests that relying on admittance calculations to map $\mu_{2}$ may be too simplistic and that more direct estimation from altimetry and hydrodynamics may be necessary.

[50] In the diurnal band the GOT fields for $2 Q_{1}, J_{1}$, and $\mathrm{OO}_{1}$ are also all extrapolated from admittances, but their errors appear fairly small. The rms for $\mathrm{OO}_{1}$ is larger than
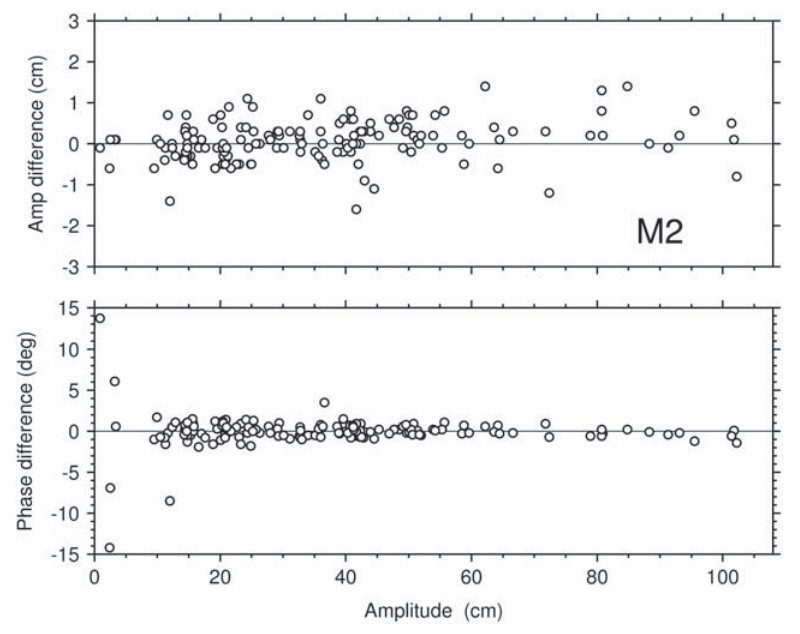

Figure 8. Differences between BPR station tides and model GOT4.8 for $\mathrm{M}_{2}$ (top) amplitudes and (bottom) phases as a function of station amplitude. Differences are in the sense: (model minus station). There are 151 difference pairs in each panel. For amplitudes greater than 45 $\mathrm{cm}$, there is a tendency for GOT4.8 amplitudes to slightly exceed the BPR amplitudes. 

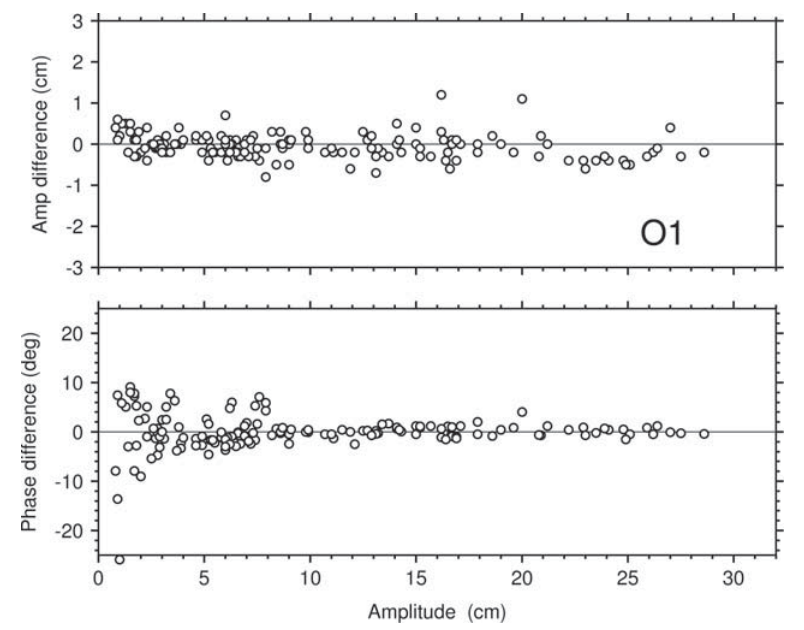

Figure 9. As in Figure 8 except for tidal constituent $\mathrm{O}_{1}$.

$\mathrm{J}_{1}$, even though its amplitude is generally smaller, but this is not unexpected since $\mathrm{OO}_{1}$ is being extrapolated over a greater range of frequency.

[51] Finally, the differences in Table 2 for $\mathrm{S}_{1}$ also look large in relation to the constituent's generally small size. This too is not unexpected. $\mathrm{S}_{1}$ is notoriously difficult to measure - a multitude of systematic errors occur at the frequency of precisely 1 cycle/day-and because its proximate cause is the $S_{1}$ atmospheric tide it is subject to a fair amount of temporal variability.

[52] Aside from testing and comparing ocean-tide models, the new bottom-pressure data set can be used to examine interesting secondary features. The next two sections offer two examples, exploiting the fact that the BPR data are sensitive to atmospheric tides while altimetry is not (section 4) while the altimetry is sensitive to the solid-earth tide while the BPR data are not (section 5).

\section{Detection of Atmospheric Tides}

[53] As noted earlier, the BPR tidal data have been corrected to remove the effects of atmospheric tides. This section analyzes the extent to which this removal is both necessary and successful. Atmospheric tides impact the bottom pressure in two ways: (1) they directly add to the measured pressure by as much as $1-2 \mathrm{hPa}$ and (2) they induce a dynamic ocean response, the so-called radiational tide. The latter is rightly considered part of the ocean tide and is not to be removed. Removal of the direct effect requires a model, either numerical or analytic, of the atmospheric tide.

[54] The dominant barometric tide over the oceans is the solar $\mathrm{S}_{2}$. For this constituent, three models are here tested. The simplest is an analytic model given by Haurwitz and Cowley [1973], which is dependent only on latitude $\phi$ and time:

$$
p(\varphi, t)=1.161 \cos ^{3} \varphi \sin \left(2 t^{\prime}+159 \mathrm{deg}\right),
$$

in $\mathrm{hPa}$, where $t^{\prime}$ is local time in appropriate units. A second model is based on an analysis [Ray and Ponte, 2003] of $6 \mathrm{~h}$ surface pressure data in the operational analysis product of the European Centre for Medium-Range Weather Forecasts (ECMWF). Because $6 \mathrm{~h}$ sampling is inadequate to define $\mathrm{S}_{2}$, constraints were invoked concerning phase propagation to yield a realistic tide, although the result was possibly too zonally symmetric (see cited paper for details). Comparison with barometric station data showed reasonably good agreement, but it did reveal a 20 min timing discrepancy, which was corrected in the final phase data. A third model is also based on tidal analysis of ECMWF operational surface pressure data, but $3 \mathrm{~h}$ rather than $6 \mathrm{~h}$ data, thus negating the need for assumptions about phase propagation. These results were kindly provided by Jean-Paul Boy (University of Strasbourg). Analysis of both ECMWF models included annual modulations, for both $\mathrm{S}_{1}$ and $\mathrm{S}_{2}$, which yields equivalent constituents $\mathrm{P}_{1}, \mathrm{~K}_{1}, \mathrm{R}_{2}$, and $\mathrm{T}_{2}$.

[55] Table 4 presents the main results of adjusting the BPR data for atmospheric tides, again using GOT4.8 as the comparison altimeter-based model. For these tests, a couple of points about the altimeter processing are relevant. Before tidal analysis the altimeter data were corrected for atmospheric loading, but only at frequencies below the tidal bands. This ensures that all tidal signals in the altimetry, including the radiational tides, are left intact and uncorrupted by any tidal signals in the air pressure fields. Secondly, some of the altimetric tidal constituents of Table 4 were not estimated directly but were inferred through admittance relationships based on the gravitational potential. For example, the $T_{2}$ constituent was inferred from $\mathrm{S}_{2}$ under the assumption that radiational forcing is minimal in both, which to first order is probably satisfactory. Constituent $\mathrm{R}_{2}$ cannot be so inferred, however, since its gravitational forcing is so weak that radiational forcing is often dominant. Thus, $\mathrm{R}_{2}$ is not included in the table.

Table 4. Air-Tide Tests: RMS Differences (cm) for Model GOT4. $8^{\mathrm{a}}$

\begin{tabular}{lccccccc}
\hline Air-Tide Model & $\mathrm{P}_{1}$ & $\mathrm{~S}_{1}$ & $\mathrm{~K}_{1}$ & $\mathrm{~T}_{2}$ & $\mathrm{~S}_{2}$ & $\mathrm{~K}_{2}$ & $\mathrm{~S}_{2}(4.8 \mathrm{a})$ \\
\hline $\begin{array}{l}\text { None } \\
\text { Analytic }\end{array}$ & 0.219 & 0.416 & 0.275 & 0.157 & 1.010 & 0.209 & 0.921 \\
ECMWF 6 h operational, 1986-1998 $^{\mathrm{c}}$ & 0.241 & 0.307 & 0.280 & 0.140 & 0.372 & 0.376 & 0.209 \\
ECMWF 3 h operational, 2000-2006 ${ }^{\mathrm{d}}$ & 0.232 & 0.303 & 0.258 & 0.139 & 0.371 & 0.208 & 0.334 \\
Bootstrap $\sigma$ & 0.022 & 0.022 & 0.018 & 0.015 & 0.023 & 0.016 & 0.023 \\
\hline
\end{tabular}

${ }^{\mathrm{a}}$ Based on 39 BPR stations in tropical latitudes.

${ }^{\mathrm{b}}$ From Haurwitz and Cowley [1973]

${ }^{\mathrm{c}}$ From Ray and Ponte [2003].

${ }^{\mathrm{d}}$ Air tides computed by J.-P. Boy, personal communication. 
RAY : BOTTOM-PRESSURE AND ALTIMETRIC TIDES

Table 5. Love Number $h_{2}$ (Real Component)

\begin{tabular}{|c|c|c|c|c|}
\hline Authors & Method & $\mathrm{M}_{2}$ & $\mathrm{O}_{1}$ & $\mathrm{~K}_{1}$ \\
\hline Dehant et al. [1999] & Theory & 0.6106 & 0.6046 & 0.5222 \\
\hline IERS Conventions 2010 & Theory & 0.6078 & 0.6028 & 0.5236 \\
\hline Herring and Dong [1994] & VLBI & $0.604 \pm 0.002$ & & \\
\hline Ray et al. [1995] & Altimetry & $0.613 \pm 0.007$ & $0.594 \pm 0.013$ & $0.512 \pm 0.012$ \\
\hline Haas and Schuh [1996] & VLBI & $0.600 \pm 0.001$ & $0.606 \pm 0.002$ & $0.496 \pm 0.002$ \\
\hline Haas and Schuh [1997] & VLBI & $0.600 \pm 0.001$ & $0.612 \pm 0.002$ & $0.512 \pm 0.003$ \\
\hline Wu et al. [2001] & SLR & $0.606 \pm ?$ & $0.618 \pm ?$ & $0.502 \pm ?$ \\
\hline Rutkowska and Jagoda [2010] & SLR & $0.6151 \pm 0.0008$ & & \\
\hline Krásná et al. [2013] & VLBI & $0.6072 \pm 0.0003$ & $0.6026 \pm 0.0009$ & $0.5267 \pm 0.0007$ \\
\hline This paper ${ }^{\mathrm{a}}$ & Altimetry & $0.611 \pm 0.003$ & $0.610 \pm 0.006$ & $0.540 \pm 0.006^{\mathrm{b}}$ \\
\hline
\end{tabular}

${ }^{a}$ Listed uncertainties for this line correspond to one standard error.

${ }^{\mathrm{b}}$ After correcting altimetry for FCN effect in load tide; otherwise 0.543 .

[56] The rms values of Table 4 are based only on 39 stations in tropical latitudes, since the air tide is very small outside this band. The air tide is very clearly detected in the altimeter-BPR differences for the main tides $\mathrm{S}_{2}$ and $\mathrm{S}_{1}$. The rms reduction for $S_{2}$ is especially pronounced, dropping from $1.01 \mathrm{~cm}$ to $0.37 \mathrm{~cm}$. The air tide is marginally detected in the annual sidelines $\mathrm{T}_{2}$ and $\mathrm{K}_{1}$ (at least for the 3-h ECMWF model). It is not detected at $\mathrm{P}_{1}$, since the rms values increase for both ECMWF models. For all constituents but one, and especially for $\mathrm{K}_{1}$, the lowest rms values are produced by the $3 \mathrm{~h}$ version of the ECMWF model. However, in light of the bootstrap-based standard errors, none of the differences between ECMWF models is significant, except for $\mathrm{K}_{1}$ for which the reduction in rms does just exceed $1-\sigma$.

[57] The final column of Table 4 uses a variant of GOT4.8, discussed in Appendix A, in which the altimetry is corrected for crustal loading by the $\mathrm{S}_{2}$ atmospheric tide, a correction that has been hitherto always ignored. It shows a further reduction in the rms, suggesting the correction is now warranted. See Appendix A for further discussions.

[58] Finally, an attempt was made to detect the lunar barometric tide by using the same approach with a model based approximately on Haurwitz and Cowley [1969]. The lunar tide, however, never exceeds 0.07 $\mathrm{hPa}$, and so it is probably unsurprising that the effect on altimeter-BP differences was negligible and the tide was not detectable.

\section{Estimation of Solid Body Tides}

[59] One possible contributor to differences between the altimetric tides and the bottom-pressure tides are errors in the adopted model of the solid body tide used to correct the satellite altimeter data. Thus, an analysis of altimeter-BP differences can conceivably be used to constrain models of the body tide and to estimate body-tide Love numbers. An early attempt to do this [Ray et al., 1995] was encouraging and found to be competitive with Love number estimates obtained from very long baseline interferometry (VLBI) [e.g., Mitrovica et al., 1994]. Our current BPR data set is much more accurate than that earlier tide-gauge data set. It appears, however, that VLBI data and analyses have improved considerably more. In principle, one expects
VLBI to be the preferred method, since it measures the solid tide without the possible masking effects of inconsistent (and much larger) ocean tide signals in the altimeterBP differences.

[60] Let $(\theta, \varphi)$ be spherical polar coordinates and $t$ be time. The expression for the body tide of any constituent of degree-2 and species $m$ ( 1 for diurnal waves, 2 for semidiurnal), with frequency $\omega$, is given by

$$
b(\theta, \varphi, t)=h_{2} \tilde{H} \cos (\omega t+m \varphi) P_{2}^{m}(\cos \theta)
$$

where $P_{2}^{m}(\cos \theta)$ is the associated Legendre function. The amplitude $\tilde{H}$ is taken from the harmonic expansion of the tidal potential [Cartwright and Edden, 1973]; for example, for $\mathrm{M}_{2}$ we have $\tilde{H}=8.1367 \mathrm{~cm}$ (taking $63.194 \mathrm{~cm}$ from the Cartwright-Edden tables and scaling by their normalization factor $\left.(5 / 96 \pi)^{1 / 2}\right)$. The Love number $h_{2}$ is taken as strictly real because (it turns out) standard errors are comparable or larger than anticipated imaginary components, which for $\mathrm{M}_{2}$ is thought to be roughly $0.002-0.003$, corresponding to an anelastic lag of $0.2^{\circ}$ [Mathews et al., 1997].

[61] Table 5 presents a compilation of theoretical and empirical estimates of the real part of $h_{2}$, including a value recommended by the International Earth Rotation and Reference System Service (IERS) Conventions [Petit and Luzum, 2010], the latter being mostly consistent with theoretical calculations by Mathews et al. [1997]. There is a fair amount of scatter among estimates at the level of a few percent, yet all clearly display the free core-nutation effect that arises for $\mathrm{K}_{1}$ as its Love number is suppressed relative to nominal values [e.g., Wahr, 1981].

[62] Recent VLBI estimates of Krásná et al. [2013] agree closely with IERS values, lending strong evidence that these should now be considered definitive. The new altimeter-based estimates here appear not in very good agreement with these and must be considered much less accurate than the new VLBI estimates. In fact, discrepancies among all empirical determinations of $h_{2}$, as seen in Table 5, suggest a long history of underestimating uncertainties, or at least underestimating systematic errors. It is therefore worth considering possible systematic errors that may bias the altimeter-BP estimates. The main ones are probably errors in the load tide and in the satellite orbit. 
[63] Consider first possible errors in the load tide. The component of the load tide of relevance here is the one induced by the degree-2, order- $m$ prograde component of the ocean tide:

$$
\zeta_{2, m}^{+}(\theta, \varphi, t)=D_{2, m}^{+} \cos \left(\omega t+m \varphi-\psi_{2, m}^{+}\right) P_{2}^{m}(\cos \theta)
$$

with amplitude $D_{2, m}^{+}$and phase lag $\psi_{2, m}^{+}$. Dropping common factors of $P_{2}^{2}$ and time, we may write the combined in-phase body plus load tide, to which the altimeter-BP data are sensitive, as

$$
b+L_{2, m}=h_{2} \tilde{H}+\alpha h_{2}^{\prime} D_{2, m}^{+} \cos \psi_{2, m}^{+}
$$

where $\alpha=(3 / 5)\left(\rho_{w} / \rho_{e}\right)$ for mean densities of seawater and earth, $\rho_{w}$ and $\rho_{e}$, respectively. The value of $\alpha$ is approximately 0.1125 , which is probably accurate to $\pm 1 \%$. For $\mathrm{M}_{2}$ the ocean-tide coefficients according to GOT4.8 are

$$
D_{2, m}^{+} \cos \psi_{2, m}^{+}=3.226 \cos 129.80 \mathrm{deg}=-2.065 \pm 0.017 \mathrm{~cm}
$$

where the uncertainty is taken from Egbert and Ray [2001]; uncertainties are somewhat larger for diurnal constituents. Our adopted $h_{2}^{\prime}$ from Farrell [1972] is -1.001; other published values for $h_{2}^{\prime}$ do not differ by more than 2\% [Nakada and Lambeck, 1987; Pagiatakis, 1990; Wang et al., 2012]. With nominal values of the Love numbers, the right-hand side of (4) for $\mathrm{M}_{2}$ is then $(4.95 \mathrm{~cm}+0.23$ $\mathrm{cm}$ ). So the load tide (for this degree-2 prograde component) amounts in total to about $5 \%$ of the body tide, and errors in it from errors in the ocean tide as well as errors in the various geophysical constants cannot affect body-tide estimates by more than about $0.1 \%$.

[64] An important exception, however, concerns $\mathrm{K}_{1}$, where the loading number $h_{2}^{\prime}$ displays the same core resonance effect as seen in $h_{2}$, but only for this one spherical harmonic component of the load. From Wahr and Sasao [1981] the perturbation in $h_{2}{ }^{\prime}$ at the frequency of $\mathrm{K}_{1}$ is about $15 \%$, so failing to account for this perturbation can lead to errors in the estimation of $h_{2}$ of as much as $1 \%$. In fact, accounting for this perturbation in diurnal-band tidal loads is rarely done and was not done in GOT4.8. In light of this, the altimetric fields of $\mathrm{K}_{1}$ used to produce the estimates of Table 5 have been recorrected for ocean tide loading to allow for this resonance; it reduces the size of the estimated $h_{2}$ although not nearly enough to bring it into alignment with the IERS Conventions. It is quite possible that other published estimates of Love numbers, including those using VLBI, also suffer from these errors in diurnalband load-tide corrections.

[65] Another possible source of bias in the altimeter-BP Love numbers is satellite orbit error. The primary orbital ephemerides for $\mathrm{T} / \mathrm{P}$ and Jason satellites were computed using tracking data from satellite laser ranging (SLR) and Doppler DORIS data with a heavy reliance on dynamical modeling [Lemoine et al., 2010]. Errors in the tide model adopted for the dynamical modeling can lead to tidally coherent errors in the orbit, and in the resulting sea-surface heights and thus in the estimated ocean tides, in a way discussed by Colombo [1984] and Bettadpur and Eanes [1994]. For the old Geosat ephemeris discussed by
Bettadpur and Eanes the errors were quite large, reaching even $5 \mathrm{~cm}$ in some locations. Errors are certainly smaller, perhaps even by 2 orders of magnitude, for the modern tide models used for $\mathrm{T} / \mathrm{P}$ and Jason, and we are here interested in only those errors that affect $D_{2, m}^{+} \cos \psi_{2, m}^{+}$, but the errors are surely nonzero. It is difficult to estimate this effect without knowing the true ocean-tide error. Unfortunately, estimated Love numbers are sensitive to errors of $1 \mathrm{~mm}$ or smaller in the altimetric-inferred body tide, so the altimeter estimates of $h_{2}$ may be affected. VLBI is of course immune to such errors; the SLR estimates would not be.

[66] Orbits based on GPS tracking are less sensitive to dynamical modeling errors, so an altimetric tidal solution built on such orbits (which could currently comprise Jason2 and part of the Jason-1 data) would be of interest.

\section{Summary Discussion}

[67] The new compilation of 151 precise estimates of bottom-pressure tides should prove a useful tool for assessing and comparing global ocean-tide models, and such work is in progress and will be reported elsewhere (D. Stammer, personal communication, 2012). The new data set is clearly superior to previous global compilations, as Table 3 emphasizes; rms differences for $M_{2}$ have dropped from $1.5 \mathrm{~cm}$ to $0.5 \mathrm{~cm}$. This added precision should prove useful as models are further improved for the most stringent applications (which often involve correcting geodetic measurements of various types, including satellite-to-satellite tracking).

[68] Because bottom-pressure recorders sense the atmospheric barometric tide, but satellite altimetry does not (at least not directly), the altimetric and bottom-pressure differences can detect this tide, very clearly for constituents $S_{1}$ and $S_{2}$, and more marginally for $T_{2}$ and $K_{1}$. Our data may in future contribute to testing models of the atmospheric tide, since standard meteorological stations used for such testing are confined to only land [e.g., Ray, 2001].

[69] Similarly, since satellite altimetry directly senses the geocentric tide, altimeter-BP tide differences reveal the solid-earth tide, both the body tide of spherical harmonic degree 2 and the more spatially complex load tide. Determination of the body-tide Love numbers is credible in the altimeter-BP differences for major constituents (Table 5), but they appear less precise than a recent VLBI determination [Krásná et al., 2013], which agrees closely with the IERS Conventions for $h_{2}$. The altimeter approach may be less accurate owing to some subtle systematic errors, discussed in section 5, and also because VLBI is not affected by the additional large, and possibly inconsistent, ocean signals inherent in the altimetry and bottom-pressure data.

[70] Nonetheless, detection of the body tide in altimeterBP tide differences is more straightforwardly identified than the load tide, since the former depends on only one spherical harmonic component. No attempt has been made here to isolate a possible load-tide signal in the difference data. Such an attempt would benefit from using a dense array of stations, of the sort now being employed on land with dense arrays of GPS stations [e.g., Ito et al., 2009; Yuan and Chao, 2012]. In fact, the full KESS array [Donohue et al., 2010], not decimated to a few stations as here, should be examined in this way, although, as with the 
VLBI estimates of Love numbers, we must expect that GPS data will be superior since GPS has no large ocean signal to contend with.

[71] Aside from attempts to study air or solid tides, the precise altimeter-BP differences already point to certain systematic errors that have previously been ignored in satellite altimetry. One is crustal loading by the $\mathrm{S}_{2}$ atmospheric tide; this signal has previously been absorbed into all ocean tide solutions and although small $(1.5 \mathrm{~mm})$ it is systematic and clearly detectable (Appendix A). Another systematic error involves inadequate modeling of the fluid core resonance effect in diurnal-band loading Love numbers, the theory for which was laid out by Wahr and Sasao [1981]. This error has generally been neglected in almost all geodetic applications, but it has a not insignificant contribution to the present Love number estimate for $\mathrm{K}_{1}$ and should therefore be considered in other studies requiring accurate ocean tide loading corrections, such as those using VLBI or superconducting gravimetry. A third systematic error that is clearly detectable in the altimeter-BP differences concerns the presence of the atmospheric tide in the dry-tropospheric range correction; while this is allowed for in Jason GDRs, it was previously neglected in most $\mathrm{T} / \mathrm{P}$ data processing.

[72] It is somewhat astonishing to see such tiny millimeter-level signals come into play. But as noted at the beginning of this paper, it is often down in the limits of detection that interesting new phenomena are identified. The new precise tide estimates compiled here help push forward into those limits by confirming that some of these tiny signals are indeed real.

\section{Appendix A: GOT Altimetric Tide Solutions}

[73] The altimeter-based tidal constituent data sets employed in the main part of this paper are taken from the so-called Goddard/Grenoble Ocean Tide (GOT) series. (The "Grenoble" in the acronym stems from early versions that used a finite-element hydrodynamic model from Christian Le Provost's group - at that time located in Grenoble-as a prior.) This appendix briefly describes the most recent GOT4 versions.

[74] All of the GOT series are based on empirical tidal analyses of multisatellite altimeter data. The methodology essentially follows Schrama and Ray [1994] and Ray [1999]. As in those works, tidal analyses were computed on altimetric residuals relative to an adopted prior model, which in the most recent versions was a combination of several global, regional, and local tide models blended across their mutual boundaries. In deep water standard harmonic analyses were used to estimate constituents $\mathrm{Q}_{1}, \mathrm{O}_{1}, \mathrm{~S}_{1}, \mathrm{~K}_{1}, \mathrm{~N}_{2}$, $\mathrm{M}_{2}, \mathrm{~S}_{2}, \mathrm{~K}_{2}$, and $\mathrm{M}_{4}$. Smaller constituents (e.g., $\mathrm{J}_{1}$ in Table 2) were inferred from admittances. The computed amplitude and phase data are on a $0.5^{\circ}$ global grid, which is more than adequate for the deep ocean but only marginally adequate in shelf seas and quite inadequate in coastal waters.

[75] GOT4.7 has been used in a number of applications, so it is worth beginning discussion with that version. In the deep ocean between latitudes $\pm 66^{\circ}$, which covers the domain of primary interest here, GOT4.7 was purposely based on measurements solely from Topex/Poseidon (T/P) and no data from Jason-1 or its follow-ons. The T/P and Jason satellites, it turns out, are slightly inconsistent at the period of the $\mathrm{S}_{2}$ tide, owing to some subtle and not completely understood effects dependent on solar radiation and the angle between the satellite orbit plane and the earth-sun axis, which varies at the alias period of $\mathrm{S}_{2}$ (59 days). It is thus useful for the following tests to have a tide solution derived solely from T/P data. GOT4.7 did also use data from other altimetric satellites, including ICESat, but only in regions outside the domain of our new BPR test data set. The altimeter data were adjusted for atmospheric loading by adopting an inverted-barometer model, but only at periods longer than 2 days; this ensures that tidal signals are not corrupted in any fashion by this adjustment.

[76] Some experimental GOT solutions have since been computed, which are nearly identical to 4.7, except for a few technical details. Most of these were meant to address problems with the solar constituent $\mathrm{S}_{2}$. In fact, GOT4.8 and GOT4.9 are identical to 4.7 except for $\mathrm{S}_{2}$ (and its inferred neighbor $\mathrm{T}_{2}$ ).

[77] GOT4.8 corrects a problem with the drytropospheric correction that has been used in T/P Geophysical Data Records (GDRs) since the beginning of the mission. These $\mathrm{T} / \mathrm{P}$ tropospheric corrections have been derived from 6-h ECMWF operational surface pressures. Because 6 $\mathrm{h}$ sampling is inadequate to capture the full $\mathrm{S}_{2}$ atmospheric tide signal, there is a corresponding error in the tropospheric correction at this frequency. The error is very small. The dry-tropospheric delay is given approximately by the surface pressure scaled by $-2.277 \mathrm{~mm} / \mathrm{hPa}$ [Hopfield, 1971], and since the air tide never exceeds $1.2 \mathrm{hPa}$ over the ocean, the tropospheric tide error never exceeds $3 \mathrm{~mm}$. It is, however, systematic, of hemispheric scale. For GOT4.8, this tide error in the dry-tropospheric correction was mostly removed by using the approach advocated by Ponte and Ray [2002], which requires computing $6 \mathrm{~h}$ climatological averages of the pressures and adjusting by an $\mathrm{S}_{2}$ model, here based on Ray and Ponte [2003].

[78] GOT4.9 is identical to 4.8, except that (unlike all previous GOT versions) it applied a correction to the $\mathrm{T} / \mathrm{P}$ sea-surface heights to account for movement of the $T / P$ center of mass relative to the altimeter antenna. The correction is based on the orientation of the satellite, which changed primarily according to a yaw steering procedure with the sun/orbit-plane angle, as well as on the heating of the solar panel. (In the AVISO User Handbook this is the "CG_Range_Corr" correction, based on algorithm s1038; see also Callahan [2010].) The correction is controversial because of some anomalous effects seen during the Jason-1 calibration campaign when $\mathrm{T} / \mathrm{P}$ and Jason-1 were flying in tight tandem formation.

[79] GOT4.10 is identical to 4.7, 4.8, and 4.9, except that only data from Jason-1 and Jason-2 were used, with no T/P data. Otherwise, all other processing and data were kept unchanged. Note that the dry-tropospheric correction for the Jason satellites never had the $\mathrm{S}_{2}$ air-tide error that the original $\mathrm{T} / \mathrm{P}$ data had.

[80] Finally, some of the GOT tidal solutions have been further adjusted after it was realized that altimetry can be usefully corrected for crustal loading deformation by the $S_{2}$ air tide. The radial displacement, computed by standard methods [Farrell, 1972] for loading from a global barometric model [Ray and Ponte, 2003], is never more than $1.4 \mathrm{~mm}$, so the effect has been understandably neglected, 
RAY : BOTTOM-PRESSURE AND ALTIMETRIC TIDES

Table 6. Model Versions and RMS Differences With Tropical $\mathrm{S}_{2}$ Bottom-Pressure Stations

\begin{tabular}{lcccccc}
\hline & Used Topex & Used Jason & Corrected Dry-Trop & Applied T/P C_g & Corrected Air-Tide Load & RMS (cm) \\
\hline GOT4.7 & Yes & No & No & No & No & $0.596 \pm 0.040$ \\
GOT4.8 & Yes & No & Yes & No & No & $0.371 \pm 0.023$ \\
GOT4.8a & Yes & No & Yes & Yes & No & $0.339 \pm 0.023$ \\
GOT4.9 & Yes & No & Yes & & No & $0.507 \pm 0.028$ \\
GOT4.10 & No & Yes & & Yes & $0.306 \pm 0.023$ \\
GOT4.10a & No & Yes & & & & $0.273 \pm 0.021$ \\
\hline
\end{tabular}

but it can influence results at the precisions now reached. The correction was applied only to GOT4.8 and 4.10, and these variants are here distinguished by an additional suffix "a" in their names.

[81] Table 6 summarizes the major differences between these GOT solutions and also tabulates the rms differences between the $\mathrm{S}_{2}$ solutions and the set of bottom-pressure tide stations described in the main part of the paper. Similar to Table 4, only tropical stations have been used because these effects are most pronounced in low latitudes. (The main conclusions apply also if the full set of 151 stations is used, but the rms differences are slightly more similar among models.) The tabulated standard errors were computed as above via a bootstrap resampling.

[82] Several conclusions are evident in the rms statistics of Table 6. The altimeter-minus-pressure differences are clearly precise enough to show: (1) the revised drytroposphere correction for $\mathrm{T} / \mathrm{P}$ is very beneficial even though the original air-tide error was no larger than $\pm 3 \mathrm{~mm}$; (2) the correction of satellite altimetry for crustal loading by the $\mathrm{S}_{2}$ air tide is beneficial; and (3) the centerof-mass correction for $\mathrm{T} / \mathrm{P}$ appears problematic. Less clearly, but probably significant because the effect is at the $2 \sigma$ level, the differences between GOT4.8 and 4.10 again highlight an inherent inconsistency between $\mathrm{T} / \mathrm{P}$ and the two Jason satellites, with the rms statistics perhaps suggesting Jason the more accurate. One might speculate whether another correction for $\mathrm{T} / \mathrm{P}$, similar but different from the center-of-mass correction now available, might bring $\mathrm{T} / \mathrm{P}$ and Jason into better consistency, but it is unclear at this point how this might be done. The results do suggest that further studies of the T/P and Jason- 1 tandem campaign are still warranted. The inconsistency clearly affects present and future tidal modeling, since it is unclear how the two satellites should be weighted in altimetric assimilation and inversions. But it also contributes to the 59 day oscillations seen in time series of global mean sea level [e.g., Masters et al., 2012], since no one tide model-even one that absorbs other altimetric errors - can consistently remove the 59 day signals throughout the whole combined time series.

\section{Appendix B: Modeling Solid Tides in Altimetry}

[83] For the analyses in section 5, it is worth noting how the solid tide has been handled in the altimetric tide solutions. The solid tide is here considered comprising two parts: a body tide forced by the astronomical tidal potential, and a smaller, more complex, load tide forced by crustal loading from the weight of the overlying ocean tide.

[84] In nearly all altimeter tidal analyses the body tide is removed as a prior correction to the altimetric sea-surface heights. On both T/P and Jason Geophysical Data Records (GDRs) the body tide has been computed from a harmonic expansion of the tidal potential [Cartwright and Edden, 1973], extrapolated from 1960 to the 2000 era, with adopted real Love numbers $h_{2}=0.609$ and $h_{3}=0.291$, held fixed for all frequencies of degree- 2 and degree- 3 tides, respectively, except that $h_{2}$ was reset to 0.52 for $\mathrm{K}_{1}$ and its two largest nodal lines. The latter reflects dependence of the $h_{2}$ Love number on the resonance effect of the fluid core [Wahr, 1981]; the GDR algorithm neglects even larger resonance effects at other constituents (e.g., $\psi_{1}$ ), but the body-tide displacement errors are small because the constituents themselves are so small.

[85] The GDR Love numbers are not consistent with IERS Conventions [Petit and Luzum, 2010]. The value 0.609 corresponds to results obtained by Wahr [1981] for semidiurnal frequencies, and the value 0.52 corresponds to his result for the main $\mathrm{K}_{1}$ line, but not the nodal lines nor any other diurnal line. Long time series of synthetic body tides, generated at latitude $30^{\circ} \mathrm{N}$ with the GDR algorithm and with the IERS algorithm, give an rms difference of $1.2 \mathrm{~mm}$; the most divergent frequency is at $\mathrm{P}_{1}$, where the core resonance effect is still significant (Wahr gives $h_{2}=0.581$ for $\mathrm{P}_{1}$ ).

[86] Unlike the body-tide correction, the load-tide correction is a posterior one, determined after tidal analysis of the altimetry has yielded a combined ocean plus load tide. The load tide consistent with this solution can then be computed by an iterative method (Cartwright and Ray, 1991, Appendix). For this, the loading numbers $h_{2}^{\prime}$ from Farrell [1972] were adopted.

[87] Acknowledgments. A number of scientists have contributed data to this project. I am indebted to Doug Luther and Chris Hughes for sending tidal harmonic constants from several recent bottom-pressure campaigns, including HOME and RAPID. Doug Luther and Martin Guiles also reanalyzed the old BEMPEX data. Chris Hughes, Randy Watts, and Karen Tracey provided recently obtained BPR time series data which were included in the new tidal analyses here. I avoided much tedious, timeconsuming effort when Andreas Macrander graciously provided his edited time series from many of the DART stations. Jean-Paul Boy helped with analysis of atmospheric tides. Discussions with Chris Garrett, Chris Hughes, Doug Luther, and David Cartwright are much appreciated. This work was supported by the National Aeronautics and Space Administration's Ocean Surface Topography project.

\section{References}

Bettadpur, S. V., and R. J. Eanes (1994), Geographical representation of radial orbit perturbations due to ocean tides: Implications for satellite altimetry, J. Geophys. Res., 99, 24,883-24,894. 


\section{RAY: BOTTOM-PRESSURE AND ALTIMETRIC TIDES}

Callahan, P. (2010), Overview of the TOPEX center of mass correction (s1038_cg_corr), paper presented at the Ocean Surface Topography Science Team Meeting, Lisbon.

Cartwright, D. E. (1975), A subharmonic lunar tide in the seas off western Europe, Nature, 257, 277-280.

Cartwright, D. E., and A. C. Edden (1973), Corrected tables of tidal harmonics, Geophys. J. R. Astron. Soc., 33, 253-264.

Cartwright, D. E., and R. D. Ray (1991), Energetics of global ocean tides from Geosat altimetry, J. Geophys. Res., 96, 16,897-16,912.

Cartwright, D. E., and B. D. Zetler (1985), Pelagic Tidal Constants 2, Publ. Sci. 33, Int. Assoc. Phys. for the Sci. Ocean, Paris.

Cartwright, D. E., W. Munk, and B. D. Zetler (1969), Pelagic tidal measurements: A suggested procedure for analysis, Eos Trans. $A G U, 50$, 472-477.

Cartwright, D. E., B. D. Zetler, and B. V. Hamon (1979), Pelagic Tidal Constants, Publ. Sci. 30, Int. Assoc. for the Phys. Sci. of the Ocean, Paris.

Colombo, O. L. (1984), Altimetry, orbits, and tides, NASA Tech. Memo., 86180 .

Dehant, V., P. Defraigne, and J. M. Wahr (1999), Tides for a convective earth, J. Geophys. Res., 104, 1035-1058.

Donohue, K., P. Hamilton, K. Leaman, R. Leben, M. Prater, R. Watts, and E. Waddell (2006), Exploratory study of deepwater currents in the Gulf of Mexico, Tech. Rep. MMS 2006-073, U.S. Dep. of Inter., New Orleans, La.

Donohue, K., P. Hamilton, R. Leben, R. Watts, and E. Waddell (2008), Survey of deepwater currents in the northwestern Gulf of Mexico, Tech. Rep. MMS 2008-030, U.S. Dep. of Inter., New Orleans, La.

Donohue, K. A., D. R. Watts, K. L. Tracey, A. D. Greene, and M. Kennelly (2010), Mapping circulation in the Kuroshio Extension with an array of current and pressure recording inverted echo sounders, J. Atmos. Oceanic Technol., 27, 507-527.

Douillet, P. (1998), Tidal dynamics of the southwest lagoon of New Caledonia: Observations and 2D numerical modelling, Oceanol. Acta, 21, 69-79.

Dushaw, B. D., P. F. Worcester, and M. A. Dzieciuch (2011), On the predictability of mode-1 internal tides, Deep Sea Res., Part I, 58, 677-698.

Egbert, G. D., and R. D. Ray (2001), Estimates of $\mathrm{M}_{2}$ tidal energy dissipation from Topex/Poseidon altimeter data, J. Geophys. Res., 106, 22,47522,502.

Elipot, S., C. Hughes, S. Olhede, and J. Toole (2013), Coherence of western boundary pressure at the RAPID WAVE array: Boundary wave adjustments or deep western boundary current advection?, J. Phys. Oceanogr., 43, 744-765.

Eyries, M., M. Dars, and L. Erdely (1964), Marégraphie par grand fond, Cahiers Oceanogr., 16, 781-798.

Farrell, W. E. (1972), Deformation of the earth by surface loads, Rev. Geophys. Space Phys., 10, 761-797.

Farrow, G. E., and K. M. Brander (1971), Tidal studies on Aldabra, Philos. Trans. R. Soc. B, 260, 93-121.

Filloux, J. H., D. S. Luther, and A. D. Chave (1991), Update on seafloor pressure and electric field observations from the north-central and northeastern Pacific: Tides, infratidal fluctuations, and barotropic flow, in Tidal Hydrodynamics, edited by B. B. Parker, pp. 617-639, John Wiley, New York.

Fu, L.-L., D. Alsdorf, R. Morrow, and E. Rodriguez (2012), SWOT: the Surface Water and Ocean Topography mission: Wide-swath altimetric measurement of water elevation on earth, Tech. Rep. Publ. 12-05, Jet Propulsion Lab, Pasadena, Calif.

Gwinn, C. R., T. A. Herring, and I. I. Shapiro (1986), Geodesy by radio interferometry: Studies of the forced nutations of the earth: 2. Interpretation, J. Geophys. Res., 91, 4755-4765.

Haas, R., and H. Schuh (1996), Determination of frequency dependent Love and Shida numbers from VLBI data, Geophys. Res. Lett., 23, 1509-1512.

Haas, R., and H. Schuh (1997), Determination of tidal parameters from VLBI data, Marees Terr. Bull. d'Info., 127, 9778-9786.

Haurwitz, B., and A. D. Cowley (1969), The lunar barometric tide, its global distribution and annual variation, Pure Appl. Geophys., 77, 122-150.

Haurwitz, B., and A. D. Cowley (1973), The diurnal and semidiurnal barometric oscillations, global distribution and annual variation, Pure Appl. Geophys., 102, 193-222.

Herring, T. A., and D. Dong (1994), Measurement of diurnal and semidiurnal rotational variations and tidal parameters of Earth, J. Geophys. Res., 99, 18,051-18,071.
Hopfield, H. S. (1971), Tropospheric effect on electromagnetically measured range: Prediction from surface weather data, Radio Sci., 6, 357-367.

Hughes, C. W., V. N. Stepanov, L.-L. Fu, B. Barnier, and G. W. Hargreaves (2007), Three forms of variability in Argentine Basin ocean bottom pressure, J. Geophys. Res., 112, C01011, doi:10.1029/2006JC003679.

Ito, T., M. Okubo, and T. Sagiya (2009), High resolution mapping of earth tide response based on GPS data in Japan, J. Geodyn., 48, 253-259.

Kanzow, T., U. Send, W. Zenk, A. D. Chave, and M. Rhein (2006), Monitoring the integrated deep meridional flow in the tropical North Atlantic: Long-term performance of a geostrophic array, Deep Sea Res., Part I, 53, 528-546.

Krásná, H., J. Böhm, and H. Schuh (2013), Tidal Love numbers estimated by geodetic VLBI, J. Geodyn., 70, 21-27.

Larsen, L. H., and J. D. Irish (1975), Tides at Cobb Seamount, J. Geophys. Res., 80, 1691-1695.

Lemoine, F. G., et al. (2010), Towards development of a consistent orbit series for TOPEX, Jason-1, and Jason-2, Adv. Space Res., 46, 1513-1540.

Lyard, F., F. Lefevre, T. Letellier, and O. Francis (2006), Modelling the global ocean tides: Modern insights from FES2004, Ocean Dyn., 56, 394-415.

Macrander, A., C. Böning, O. Boebel, and J. Schröter (2010), Validation of GRACE gravity fields by in-situ data of ocean bottom pressure, in System Earth Via Geodetic-Geophysical Techniques, edited by F. Flechtner et al., pp. 169-185, Springer, Berlin.

Malin, S. R. C., and S. Chapman (1970), The determination of lunar daily geophysical variations by the Chapman-Miller method, Geophys. J. R. Astron. Soc., 19, 15-35.

Masters, D., R. S. Nerem, C. Chow, E. Leuliette, B. Beckley, N. White, and M. Ablain (2012), Comparison of global mean sea level time series from Topex/Poseidon, Jason-1, and Jason-2, Mar. Geodesy, 35, 20-41.

Mathews, P. M., V. Dehant, and J. M. Gipson (1997), Tidal station displacements, J. Geophys. Res., 102, 20,469-20,477.

Miller, A. J., D. S. Luther, and M. C. Hendershott (1993), The fortnightly and monthly tides: Resonant Rossby waves or nearly equilibrium gravity waves?, J. Phys. Oceanogr., 23, 879-897.

Mitrovica, J. X., J. L. Davis, P. M. Mathews, and I. I. Shapiro (1994), Determination of the tidal $h$ Love number parameters in the diurnal band using an extensive VLBI data set, Geophys. Res. Lett., 21, 705-708.

Munk, W. H., and D. E. Cartwright (1966), Tidal spectroscopy and prediction, Philos. Trans. R. Soc. A, 259, 533-581.

Nakada, M., and K. Lambeck (1987), Glacial rebound and relative sea-level variations: a new appraisal, Geophys. J. R. Astron. Soc., 90, 171-224.

Pagiatakis, S. D. (1990), The response of a realistic earth to ocean tide loading, Geophys. J. Int., 103, 541-560.

Petit, G., and B. Luzum, Eds. (2010), IERS Conventions 2010, International Earth Rotation and Reference Systems Service, Verlag des Bundesamts für Kartographie und Geodäsie, Tech. Note 36.

Ponte, R. M., and R. D. Ray (2002), Atmospheric pressure corrections in geodesy and oceanography: A strategy for handling air tides, Geophys. Res. Lett., 29(24), 2153, doi:10.1029/2002GL016340.

Ray, R. D. (1999), A global ocean tide model from Topex/Poseidon altimetry: GOT99.2, NASA Tech. Memo., 209478.

Ray, R. D. (2001), Comparisons of global analyses and station observations of the $\mathrm{S}_{2}$ barometric tide, J. Atmos. Sol. Terr. Phys., 63, 1085-1097.

Ray, R. D. (2007), Propagation of the overtide $\mathrm{M}_{4}$ through the deep Atlantic Ocean, Geophys. Res. Lett., 34, L21602, doi:10.1029/2007GL031618.

Ray, R. D., and D. A. Byrne (2010), Bottom pressure tides along a line in the southeast Atlantic Ocean and comparisons with satellite altimetry, Ocean Dyn., 60, 1167-1176.

Ray, R. D., and R. M. Ponte (2003), Barometric tides from ECMWF operational analyses, Ann. Geophys., 21, 1897-1910.

Ray, R. D., S. Bettadpur, R. J. Eanes, and E. J. O. Schrama (1995), Geometrical determination of the Love number $h_{2}$ at four tidal frequencies, Geophys. Res. Lett., 22, 2175-2178.

Ray, R. D., G. D. Egbert, and S. Y. Erofeeva (2011), Tide predictions in shelf and coastal waters: Status and prospects, in Coastal Altimetry, edited by S. Vignudelli et al., chap. 8, pp. 191-216, Springer, Berlin.

Rayner, D., et al. (2011), Monitoring the Atlantic meridional overturning circulation, Deep Sea Res. Part II, 58, 1744-1753.

Rutkowska, M., and M. Jagoda (2010), Estimation of the elastic earth parameters $\left(h_{2}, l_{2}\right)$ using SLR data, Adv. Space Res., 46, 859-871.

Schrama, E. J. O., and R. D. Ray (1994), A preliminary tidal analysis of TOPEX/POSEIDON altimetry, J. Geophys. Res., 99, 24,799-24,808.

Shum, C. K., et al. (1997), Accuracy assessment of recent ocean tide models, J. Geophys. Res., 102, 25,173-25,194. 


\section{RAY: BOTTOM-PRESSURE AND ALTIMETRIC TIDES}

Smithson, M. J. (1992), Pelagic Tidal Constants 3, Publ. Sci. 35, Int. Assoc. for the Phys. Sci of the Ocean, Paris.

Snodgrass, F. (1968), Deep sea instrument capsule, Science, 162, 78-87.

Spencer, R., and J. M. Vassie (1997), The evolution of deep ocean pressure measurements in the U.K., Prog. Oceanogr., 40, 423-435.

Spencer, R., P. R. Foden, C. McGarry, A. J. Harrison, J. M. Vassie, T. F. Baker, M. J. Smithson, S. A. Harangozo, and P. L. Woodworth (1993), The ACCLAIM programme in the South Atlantic and Southern Oceans, Int. Hydrogr. Rev., 70, 7-21.

Wahr, J. M. (1981), Body tides on an elliptical, rotating, elastic and oceanless earth, Geophys. J. R. Astron. Soc., 64, 677-704.
Wahr, J. M., and T. Sasao (1981), A diurnal resonance in the ocean tide and in the earth's load response due to the resonant free 'core nutation', Geophys. J. R. Astron. Soc., 64, 747-765.

Wang, H., L. Xiang, L. Jia, L. Jiang, Z. Wang, B. Hu, and P. Gao (2012), Love numbers and Green's functions for elastic Earth models PREM, iasp91, ak135, and modified models with refined crustal structure from Crust2.0, Comput. Geosci., 49, 190-199.

Wu, B., B. B. Peng, Y. Z. Zhu, and H. Hsu (2001), Determination of Love numbers using satellite laser ranging, J. Geod. Soc. Jpn., 47, 174-180.

Yuan, L., and B. F. Chao (2012), Analysis of tidal signals in surface displacement measured by a dense continuous GPS array, Earth Planet. Sci. Lett., 355, 255-261. 